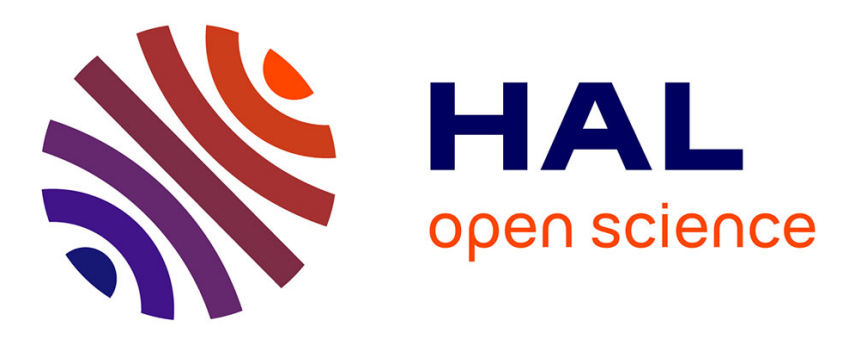

\title{
Electrochemical characterisation of fuel cell stack during cold start
}

\author{
F. Harel, S. Bégot, S. Wasterlain, D. Candusso
}

\section{To cite this version:}

F. Harel, S. Bégot, S. Wasterlain, D. Candusso. Electrochemical characterisation of fuel cell stack during cold start. European Physical Journal: Applied Physics, 2011, 54 (2), 10.1051/epjap/2010100267 . hal-00699044

\section{HAL Id: hal-00699044 \\ https://hal.science/hal-00699044}

Submitted on 19 May 2012

HAL is a multi-disciplinary open access archive for the deposit and dissemination of scientific research documents, whether they are published or not. The documents may come from teaching and research institutions in France or abroad, or from public or private research centers.
L'archive ouverte pluridisciplinaire HAL, est destinée au dépôt et à la diffusion de documents scientifiques de niveau recherche, publiés ou non, émanant des établissements d'enseignement et de recherche français ou étrangers, des laboratoires publics ou privés. 


\section{Special issue "Fuel Cells"}

\section{Electrochemical characterisation of fuel cell stack during cold start}

Fabien Harel $^{1,2}$, Sylvie Bégot ${ }^{1,3}$, Sébastien Wasterlain ${ }^{1,3}$, Denis Candusso ${ }^{1,2}$

${ }^{1}$ FC LAB, rue Thierry Mieg, 90010 BELFORT Cedex, FRANCE

2 INRETS, The French National Institute for Transport and Safety Research

${ }^{3}$ FEMTO-ST (UMR CNRS 6174), ENISYS department, UTBM-UFC

- Corresponding author: fabien.harel@,inrets.fr $\quad$ Phone : +33(0)3 84583618

Fax : $+33(0) 384583636$

- Other e-mail addresses:

sylvie.begot@univ-fcomte.fr (Sylvie Bégot)

sebastien.wasterlain@utbm.fr (Sébastien Wasterlain)

denis.candusso@inrets.fr (Denis Candusso) 


\section{Abstract}

Fuel cell self start at negative temperature conditions is not an easy task due to the water produced by the reduction of oxygen at the cathode. This amount of water can turn into ice and block the reaction before the temperature inside the fuel cell reaches positive values. The mechanism of the physical process which leads to oxidant starvation phenomena when ice appears is not yet well identified. In order to obtain a deeper understanding of this problem, the article presents some experimental investigations conducted on a short fuel cell stack. These experiments simulate vehicle technology operated in cold start conditions not with the primary objective to reach a successful and rapid start-up but much rather to characterise and understand the cold start phenomena until starvation occurs. A number of polarisation curves, electrochemical spectroscopy and cyclic voltammetry measurements are done on the stack before, after and also during the cold starts experiments. It is observed that the process of drying and cooling down prior to cold start have a great impact on the electrochemical cathode area. The results obtained show the evolution of the stack behaviour during the low temperature operation with a slow production of frost. The consequence on the individual cells in terms of inhomogeneous degradation is highlighted.

Keywords: PEM fuel cell; cold start; EIS; voltammetry

\section{Introduction}

To ensure the technological viability of Fuel Cell (FC) systems in the transportation sector, new techniques that allow FC systems to start with temperatures below zero degrees Celsius have to be developed. Since the 90's, many works have been done aiming at reaching the self start up of FCs from cold temperatures compatible with 
transportation applications [1]. Numerous patents have been registered on this subject but many of them suggest warming the FC by means of an external circuit before to start it up [2].

Many issues need to be investigated and solved. Currently, frost process in fuel cell cold start is not fully understood. Other questions are still opened: what kind of procedure should be adopted for the FC shut-off after the stack operation and before the cold start? What is the degradation type and rate of the FC performance induced by such operations?

During the last years, some advances have been made in the understanding of the frost mechanism occurring in FCs and most particularly in the spatial localisation of the frost inside the cell assembly. In this way, Pineri et al. [3] have shown that water in the FC perfluorinated membrane cooling down below $273 \mathrm{~K}$ never crystallizes. The authors conclude that upon cooling, part of the water desorbs out of the membrane and the undesorbed water becomes "glassy water" below $220 \mathrm{~K}$. It has been shown that a dried membrane can absorb the water produced during the cold start at negative temperatures, within the limits of its capacity $[4,5,6,7]$. According to [8], ice can play a blocking role in the FC operation, especially in some sections of the active layers at cathode, when active sites are obstructed and platinum particles are isolated.

Most of the works aiming at understanding the frost phenomenon and its consequences involve some electro-analytical measurement methods like Electrochemical Impedance Spectroscopy (EIS), Cyclic Voltammetry (CV), Linear Sweep Voltammetry (LSV). However, these experiments are usually conducted only on single cells and at ambient temperature, once the freezing tests are completed. The main objective of these works is thus to evaluate the effect of the cold start phase. Using this kind of methods, the works 
of Hou et al. $[9,10]$ can be mentioned. They deal with degradation aspects linked to the flushing / drying phases and report on the effects of the residual water after cold starts. Cho et al. [11] have investigated the effects of the thermal cycling $\left(-10^{\circ} \mathrm{C} /+80^{\circ} \mathrm{C}\right)$ on the Electrochemical active Area (ECA). Ozcipok et al. [12] and Wang et al. [13] worked on the degradation of the catalytic layer induced by the cold start. During cold start, EIS measurement was also studied by Oszcipok et al. In this case, a single cell with an active area of $33 \mathrm{~cm}^{2}$ was investigated at the operating temperature of $-10^{\circ} \mathrm{C}$. The results show the evolution of membrane/contact resistance and charge transfer resistance during cold start. Some CV measurements were realised by Ge et al. [14]; a single cell of $5 \mathrm{~cm}^{2}$ was considered. Using these electrochemical methods applied during the cell operation at negative temperature, it was demonstrated that the reduction of the active surface at cathode is larger when ice is present than after the thawing at positive temperature.

In contrast with single cell tests, the cold start experiments conducted on whole stacks are still now mainly focused on the study of the parameters impacting the FC assembly started in cold surround [15], the complete FC system for embedded applications [16] and the portable PEMFC [17].

In our article, a number of measurements are done on short stacks in order to obtain better comprehension and understanding of the performance distribution between the individual cells of the stack operated at negative temperature. The second aim is to discern the impact of the degradation that may not be homogeneous either. The behaviour of a 5 cell stack is studied before, during and after cold start operation. Four temperature levels have been considered: $-5^{\circ} \mathrm{C},-10^{\circ} \mathrm{C},-15^{\circ} \mathrm{C}$ and $-18^{\circ} \mathrm{C}$. The use of EIS and $\mathrm{CV}$ techniques, combined with a mastered generation of frost using a galvanostatic 
control of the electric load, allows visualising the evolution of the stack behaviour. In order to investigate the behaviour disparity between individual cells, a five cell stack configuration appears to be a good trade-off between a larger stack with a too high voltage, incompatible with most of the electrochemical workstation capabilities, and a single cell.

The target is not to have a successful FC start-up but rather to monitor and understand the physical process of frost occurrence and stress on the stack performance degradation.

\section{Experimental}

\subsection{The fuel cell}

The investigations were led on a PEMFC stack including five cells with an active area of $220 \mathrm{~cm}^{2}$. The stack is composed of commercial Membrane Electrode Assemblies (MEAs), Gas Diffusion Layers (GDLs) and thin metallic flow field plates. It is cooled by a fluid circuit that circulates inside the metallic plates. In nominal conditions, the FC is to be operated at temperature close to $80^{\circ} \mathrm{C}$ and fed by humidified hydrogen and air, with Relative Humidity (RH) rates of $50 \%$.

\subsection{The test bench}

The test bench has been developed in-lab and is dedicated to the characterisation of FCs for power less than $1 \mathrm{~kW}$ (Fig. 1). It includes a complete gas conditioning system, the electric / electronic management system, the electronic load, the FC primary water circuit dedicated to the control of the temperature inside the stack and the data acquisition system. Gas flows are controlled upstream by BROOKS 5800S Series thermal mass flow controller and the pressure is piloted downstream by KAMMER 
back pressure valves. Humidification is based on bubblers on both oxidant and reactant lines. Gas inlets can be fed either by reactant gases (air and hydrogen) or nitrogen. The test bench temperature control circuit consists of a primary circuit filled with deionised water and two secondary circuits, one for cooling, the other for heating. Primary and secondary circuits are linked between exchangers. Usually, mainly for characterisation of FC, the temperature is controlled with simple actions on normally closed solenoid valves on hot and cold secondary circuits. For the needs of the present study, the cooling circuit is here replaced by an external recirculating cooler JULABO FCW2500T. This apparatus is directly connected to the primary coolant circuit of the FC and allows controlling the stack temperature in the range of $-20^{\circ} \mathrm{C} /+80^{\circ} \mathrm{C}$. The coolant liquid is non conductive ethylene glycol. The electronic load is a TDI Dynaload RBL 100-300-2000. The data acquisition system is based on PXI/SCXI National Instruments hardware and the control software is developed with Labview ${ }^{\mathrm{TM}}$. More details about the test bench can be found in [18]. 


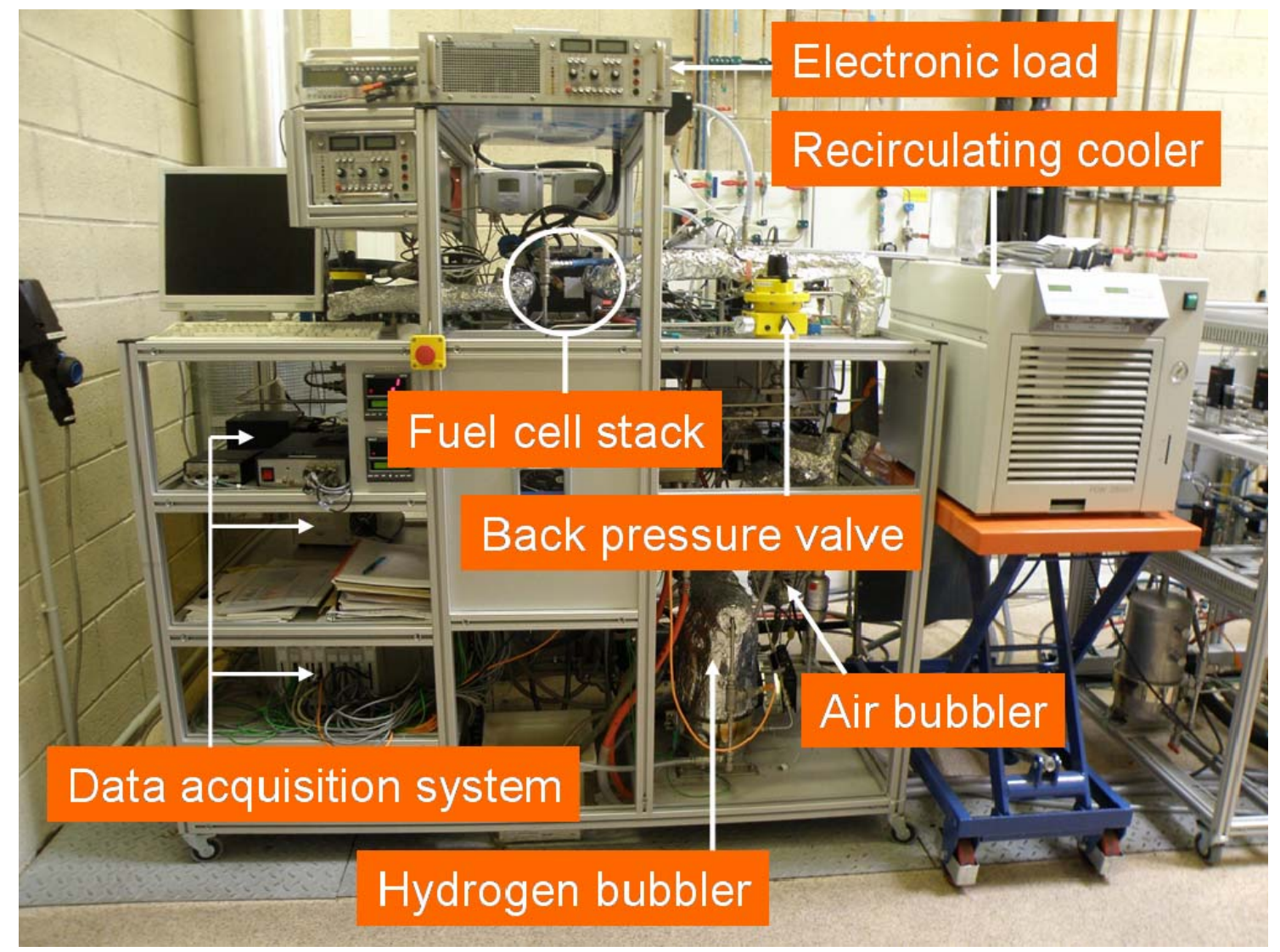

Fig. 1. Picture of the FC test bench.

\subsection{The test procedures}

\subsubsection{Conditioning Process (CP)}

Before and after each experiment in cold conditions, the FC is operated under the same procedure called Conditioning Process $(\mathrm{CP})$. The aim of this procedure is both to place the FC in a stable state for the characterisations after cold starts and recondition it before the next cold experiment. Reconditioning the FC after cold start is an important issue because previous studies have shown that two types of degradation linked to the cold experiments exist. One is irreversible and the other is reversible [14,19]. With respect to the $\mathrm{CP}$ protocol, it can be possible to assess the impact of the cold starts on performance. In that way, the FC is heated up by the coolant loop and operated during 
thirty minutes close to its nominal operating point, with the following parameters: cooling temperature $\mathrm{T}=75^{\circ} \mathrm{C}$, downstream relative pressure for air and hydrogen $\mathrm{P}=500 \mathrm{mbar}$, Relative Humidity $\mathrm{RH}=50 \%$, current density $\mathrm{j}=0.5 \mathrm{~A} \cdot \mathrm{cm}^{-2}$. During this stage, an EIS characterisation is carried out. After that, the FC is operated at a current density of $0.7 \mathrm{~A} \cdot \mathrm{cm}^{-2}$ for fifteen minutes and a polarisation curve is recorded by decreasing the load value gradually. Then, the FC temperature is decreased down to $20^{\circ} \mathrm{C}$ and purging of the anodic and cathodic compartments is used to flush the residual water in the test bench gas pipes and to dry the gas channels and the membranes of the FC. For all the tests, the drying process is applied with nitrogen on both anode and cathode. The gas flow is constant and its value corresponds to a current density of 0.5 $\mathrm{A} \cdot \mathrm{cm}^{-2}$ with stoichiometry ratios of 1.5 for the anode and 2 at the cathode. Purging is stopped when the monitored electronic resistance reaches five times its nominal value $R 1_{\text {nom }}$. The electronic resistance is measured at the frequency of $1 \mathrm{kHz}$ using a milliohmmeter (Agilent 4338B) linked to the control software by an IEEE-488 digital communication bus. Once the drying process is achieved, the purge flow is stopped and the $\mathrm{FC}$ is cooled down to the targeted cold temperature $\left(-5^{\circ} \mathrm{C},-10^{\circ} \mathrm{C},-15^{\circ} \mathrm{C}\right.$ or $\left.-18^{\circ} \mathrm{C}\right)$. Then, this temperature remains constant during 30 minutes to ensure equilibrium of temperature in the whole stack, so that isothermal cold start experiments can be performed.

\subsubsection{Cold Start Procedure (CSP)}

The FC is fed with constant flows of dry reactant gases at ambient temperature according to a current density of $90 \mathrm{~mA} \cdot \mathrm{cm}^{-2}$ at stoichiometry rates of 1.5 and 2 for anode and cathode respectively. No back pressure is applied. Once the Open Current Voltage (OCV) is established, the electronic load is connected in galvanostatic mode 
and adjusted at a current density of $9 \mathrm{~mA} \cdot \mathrm{cm}^{-2}$. This low current density value is selected in order to obtain a weak water production by the fuel cell. The consequence is a slow development of the frost phenomena that we intend to study. In this way, the procedure allows to gradually assess the evolution of the $\mathrm{FC}$ behaviour and perform measurements in quasi steady state.

\subsubsection{Electrochemical Impedance Spectroscopy (EIS)}

EIS is a well known measuring technique to investigate the electrical properties of $\mathrm{FC}$ components like membrane resistance or to highlight the relative importance of mass and charge transfer. In our tests, the measurements are carried out on the operating stack with an IM6 Zahner impedancemeter and performed in two different ways: the first one is related to cold start conditions and the other one to nominal temperature conditions. In nominal operating conditions, the recording parameters (frequency range, number of frequency points per decade, duration / number of sinus period on each point) of the EIS experiment have usual values because of the FC stability at this point. The frequency domain explored is wide and ranges from $5 \mathrm{kHz}$ to $10 \mathrm{mHz}$. The $\mathrm{FC}$ is operated with a polarisation current density of $0.5 \mathrm{~A} \cdot \mathrm{cm}^{-2}$; this value is adjusted by the electronic load. Simultaneously, the IM6 potentiostat is used in galvanostatic mode with a sinusoidal current oscillation of $+/-2 \%$ of the polarisation current density applied. During the cold starts, the EIS measurement is not easy to perform because the experiment is realised in conditions which may not be stationary (as they should be theoretically for EIS tests). In that way, the impedance spectra must be recorded on a relative short time period / interval. The frequency range applied is thus limited to the $5 \mathrm{kHz}-50 \mathrm{mHz}$ interval and the level of the current oscillation is fixed to $+/-5 \%$ of the polarisation current density. 
With these parameters, the EIS duration (complete record of the spectrum) is about 2 minutes.

\subsubsection{Cyclic Voltammetry (CV)}

$\mathrm{CV}$ is a frequently used technique to study chemical systems. It is here used to evaluate the variations of the total cathode active surface area during the different stages of the cold start. CV diagnostic tests are realised on the entire stack with the IM6 Zahner impedancemeter and its PP240 power potentiostat. During these measurements, the CSP is stopped. The counter and reference electrode is the anode of the FC and it is fed with a dry hydrogen flow equal to $1.5 \mathrm{NL} \cdot \mathrm{min}^{-1}$. The working electrode is the cathode of the stack and it is fed with a dry nitrogen flow of $1.5 \mathrm{NL} \cdot \mathrm{min}^{-1}$. When any one of the cell voltages drops down below $100 \mathrm{mV}$, the stack voltage is cycled 4 times between $0.05 \mathrm{~V}$ and $4 \mathrm{~V}$ with a slew rate of $200 \mathrm{mV} \cdot \mathrm{s}^{-1}$.

\subsubsection{Linear Scan Voltammetry (LSV)}

LSV is a powerful method to estimate the hydrogen crossover between anode and cathode in FCs. The tests are realised with the same material and procedure used for the $\mathrm{CV}$, except for the tuning of two parameters: the voltage cycle magnitude ranges from $0.1 \mathrm{~V}$ to $4 \mathrm{~V}$ and the slew rate is set to $10 \mathrm{mV} \cdot \mathrm{s}^{-1}$.

\section{Results and discussion}

\subsection{Spectroscopy experiments during cold starts}

The EIS measurements (an example of typical EIS plot is shown in Fig. 2) done during cold starts are realised on the whole stack during the development of the CSP protocol, at three different levels of start temperature $\left(-5^{\circ} \mathrm{C},-10^{\circ} \mathrm{C},-18^{\circ} \mathrm{C}\right)$. Before each experiment, the FC conditioning is ensured with the CP protocol. The evolution of the 
lowest and highest cell voltage values during corresponding temperature cold starts are given in Fig. 3 and the different instants of EIS measurements are indicated. The results of the EIS measurements done during cold starts are shown in Fig. 4. The left column of Fig. 4 shows EIS results and the right column shows the evolution of the electronic resistance $R 1$, resistance $R 2$ and resistance $R 3$ of the whole stack.

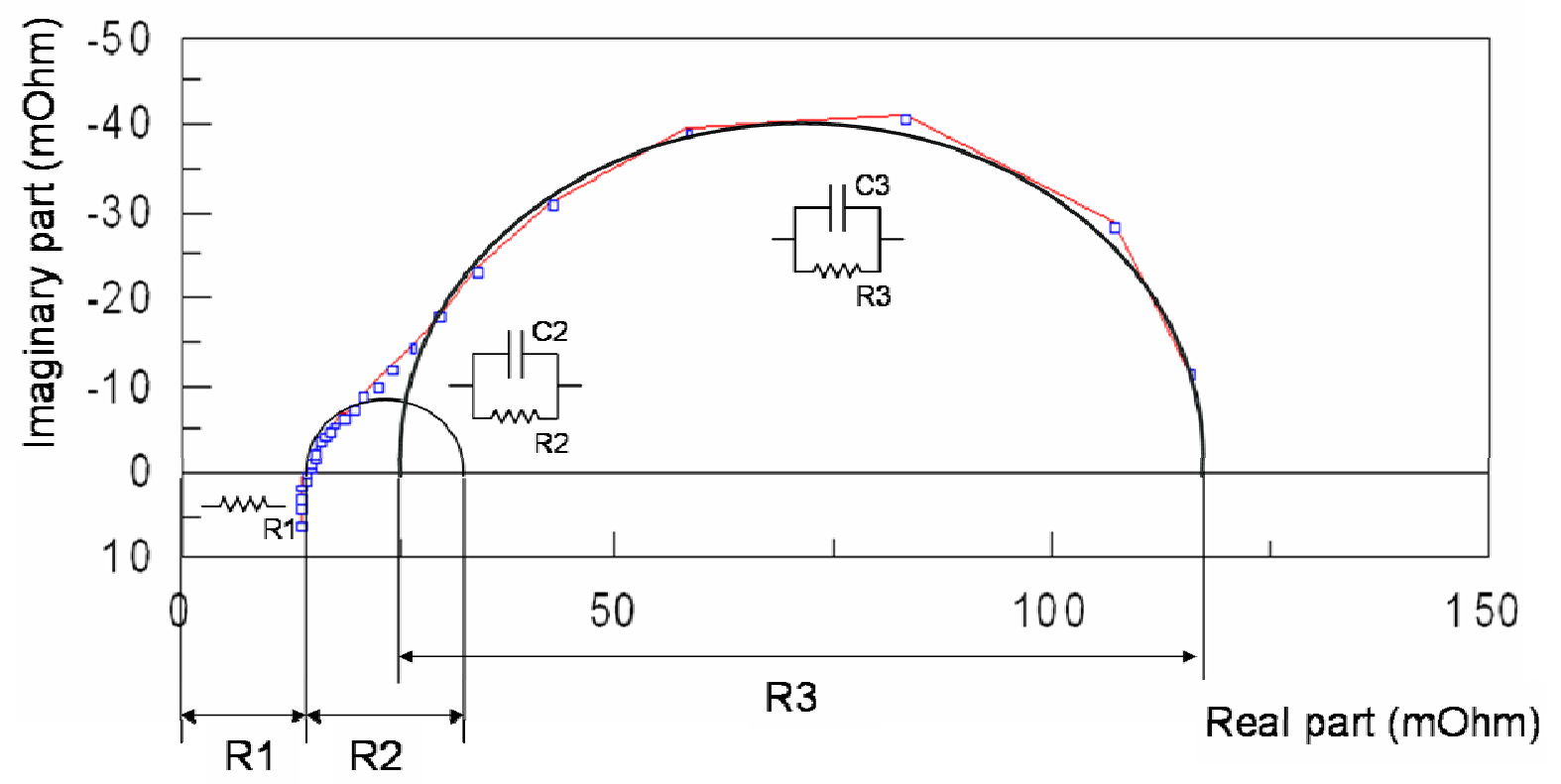

Fig. 2. Illustration of fitting on semicircular Nyquist plots

Expression of resistances $R 1, R 2, R 3$

These resistances are related to electrical equivalent circuits [20] and their values are deduced from the fitting of semicircular Nyquist plots as it is explained on Fig. 2 where the left point of intersection with the $\mathrm{x}$ axis corresponds to the electronic resistance $R 1$. The electronic resistance is the sum of the ionic resistance in the membranes plus the electrical contact resistances between the different elements of the stack (electrodes, gas diffusion layers, bipolar plates, current collectors). It is assumed that the diameter of the high frequency semicircle is representative to the charge-transfer resistance $R 2$ (transfer 
of electrons and protons at the electrodes) and the $R 3$ value, estimated from the diameter of the low frequency semicircle, is representative of slower phenomena including transfer of charges at cathode and transport of species. These values are plotted versus the water produced by one cell during the experiment. The produced water $\mathrm{mH}_{2} \mathrm{O}$ for one cell is calculated using Eq.1.

$m H_{2} \mathrm{O}_{\left(g . \mathrm{cm}^{-2}\right)}=\frac{\int_{0}^{t} j d t}{2 \mathrm{~F}} M_{\mathrm{H}_{2} \mathrm{O}}$

Where:

$j$ is the load current density $\left(\mathrm{A} \cdot \mathrm{cm}^{-2}\right)$,

$F$ is the Faraday Constant, the charge on one mole of electrons: 96485 Coulombs, $M_{\mathrm{H}_{2} \mathrm{O}}$ is the molar mass of water $\left(M_{\mathrm{H}_{2} \mathrm{O}}=18 \mathrm{~g} \cdot \mathrm{mol}^{-1}\right)$

According to the experimental results shown in Fig. 3 and Fig. 4 during the CSP at three different cold start temperatures, the increase of the electronic resistance $R 1$ with the start temperature can be firstly discussed. First we should bear in mind that after applying the $\mathrm{CP}$ protocol, the $R 1$ value measured at $20^{\circ} \mathrm{C}$ is always the same, i.e. five times the nominal value. It can be seen on the initial spectra that the value of $R 1$ depends on the negative temperature level considered for the cold start test. The lower the temperature is, the higher the electronic resistance. This phenomenon is described in [3] and is linked with the water desorption in Nafion ${ }^{\circledR}$ membranes at low temperature. 

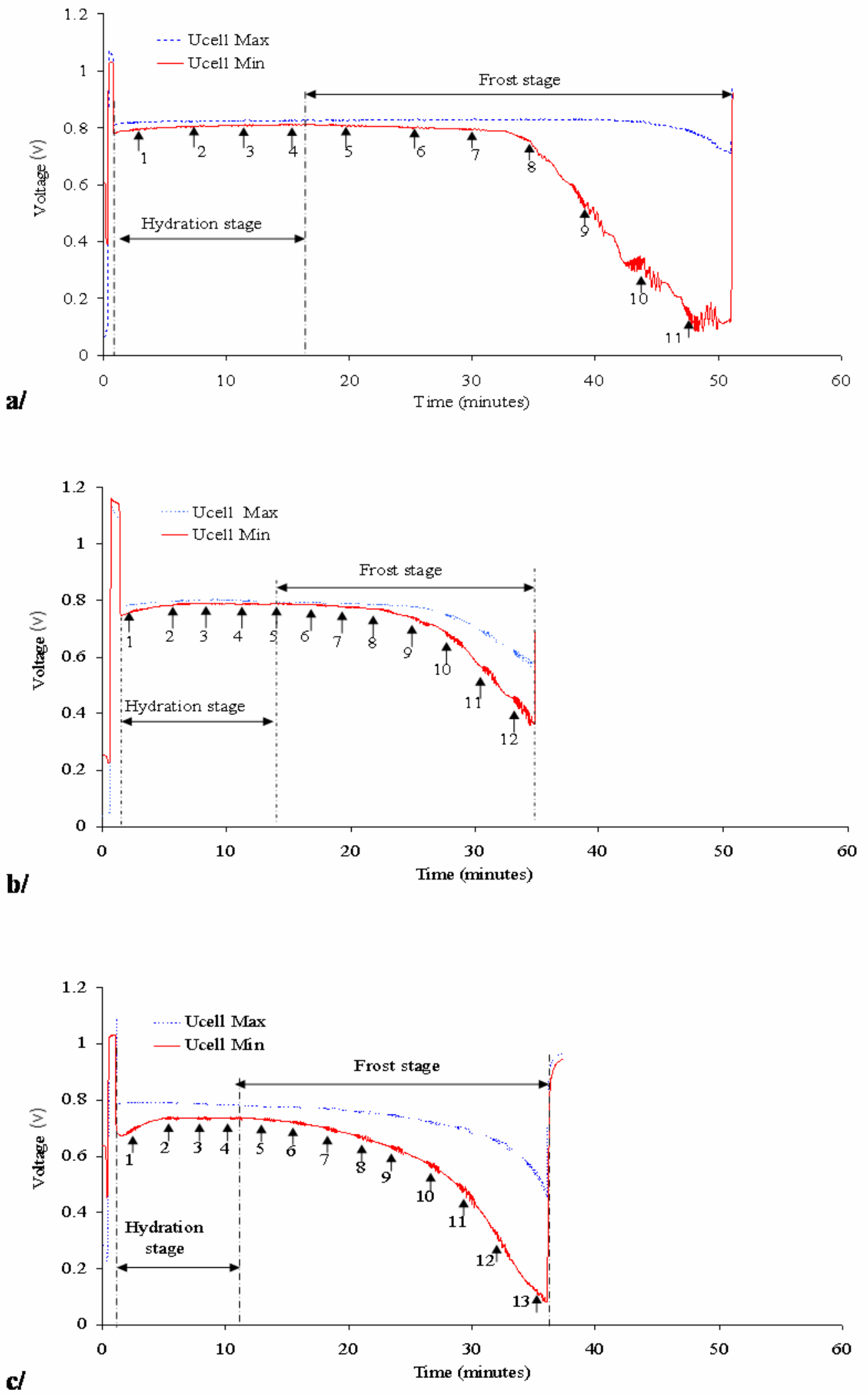

Fig. 3. Evolution of the minimal and maximal cell voltage values during cold start-up experiments $\left(\mathrm{a}:-5^{\circ} \mathrm{C}, \mathrm{b}:-10^{\circ} \mathrm{C}, \mathrm{c}:-18^{\circ} \mathrm{C}\right)$ 


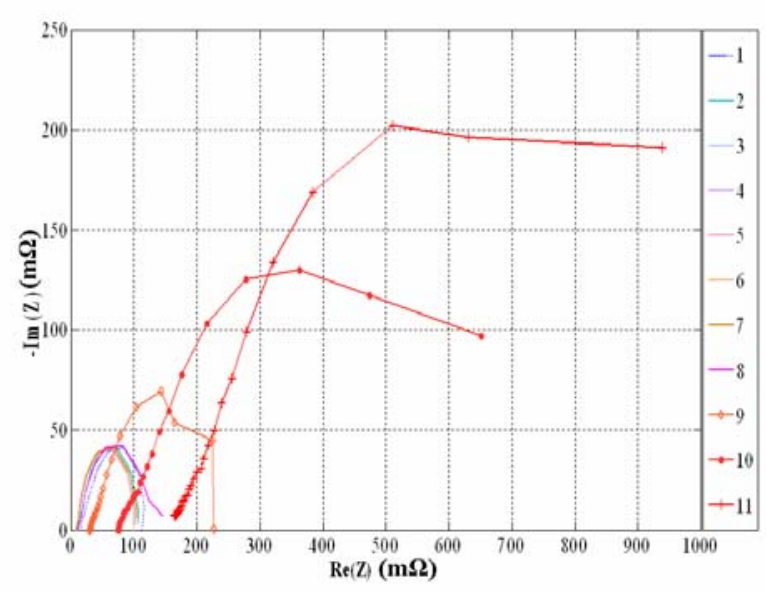

a/

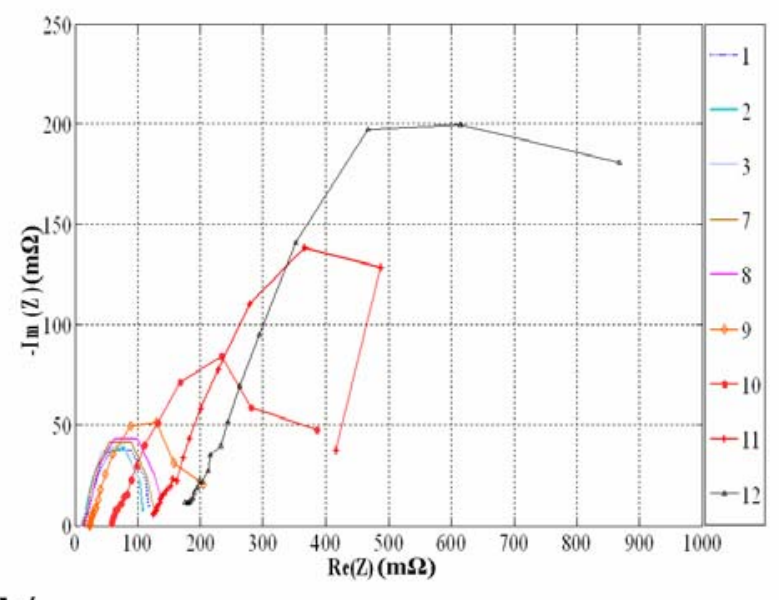

b/

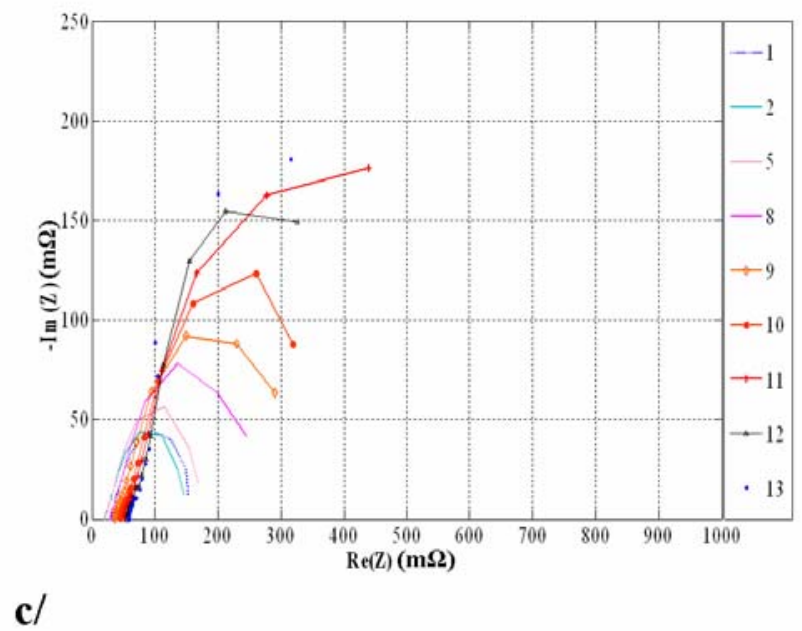

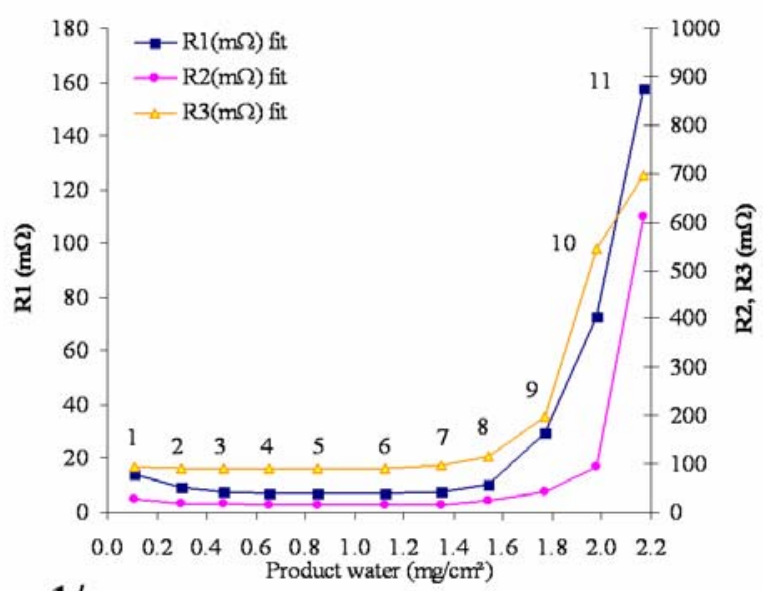

a1/
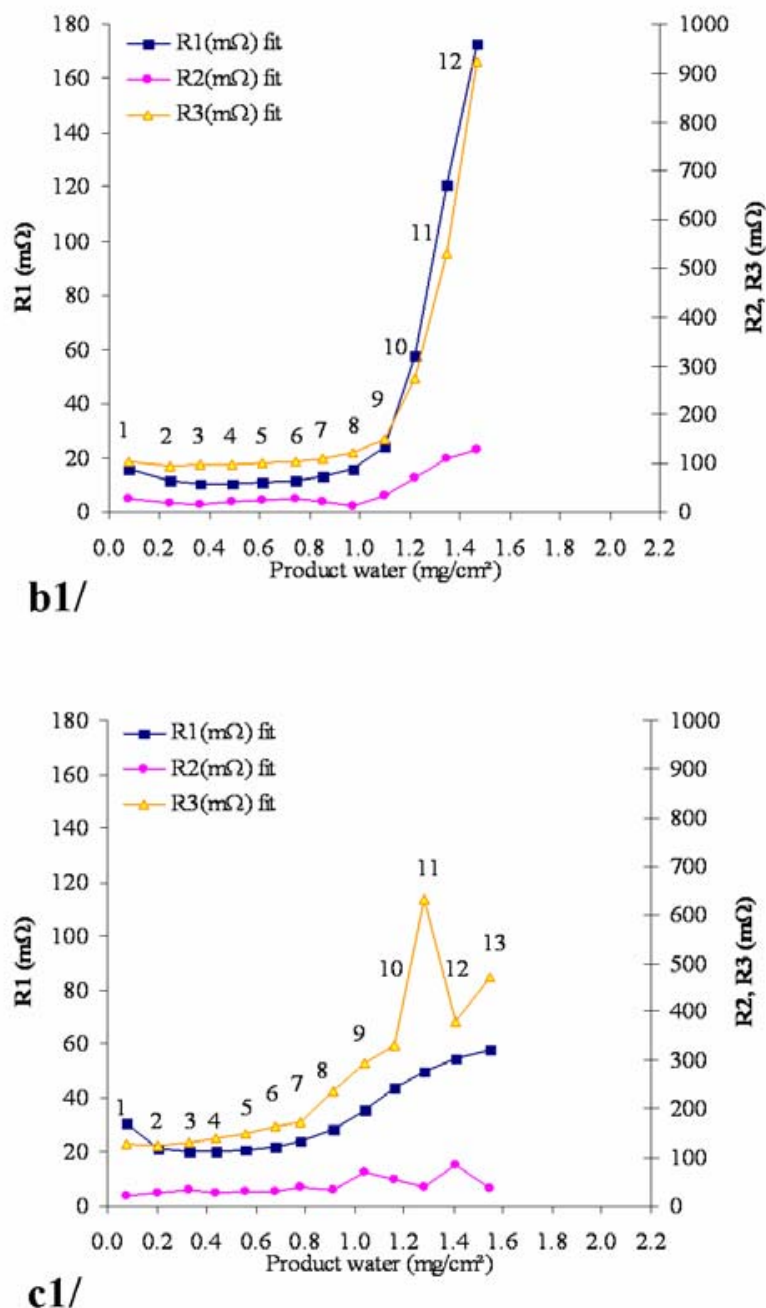

Fig. 4. Series of EIS during cold start-up experiments a):- $\left.\left.5^{\circ} \mathrm{C}, \mathrm{b}\right):-10^{\circ} \mathrm{C}, \mathrm{c}\right):-18^{\circ} \mathrm{C}$

Evolution of resistances R1, R2, R3 during cold start-up experiments a1):-5 ${ }^{\circ}$,

$$
\text { b1):- } \left.\left.10^{\circ} \mathrm{C}, \mathrm{c} 1\right):-18^{\circ} \mathrm{C}\right)
$$


The growth of the resistance is a consequence of the decrease of the liquid phase of water inside the membranes during the cooling down process. The high frequency electronic resistance during the initial spectra is $14 \mathrm{~m} \Omega$ at $-5^{\circ} \mathrm{C}, 16 \mathrm{~m} \Omega$ at $-10^{\circ} \mathrm{C}$ and $30 \mathrm{~m} \Omega$ at $-18^{\circ} \mathrm{C}$. For the three or four following spectra, it can be pointed out that there is a translation to the left on the real axis, in the direction of the electronic resistance decrease, toward a minimal value. This translation can be observed e.g. for the spectra 2, 3 and 4 in Fig. 4 a/b/c/. In the same time, in Fig. 3 a/b/c/, the fuel cell voltages increase. The decrease of the electronic resistance is related to an increase in the amount of water inside the membranes. Membranes behave in this stage like dry sponges. The water produced by the FC electrochemical reaction is absorbed by the membranes. The plot of the highest and lowest cell voltages (Ucell max and Ucell min) in Fig. 3 shows the electrical behaviour of the stack during cold starts. After the load is connected, the cell voltages increase slightly and then stabilize. This stage is called the Hydration Stage of the membranes. During this period of about fifteen minutes, no degradation of the FC performances is noticeable. The water produced on the active area does not seem to turn into ice and reach the membranes. In a second stage, the maximum membranes water uptake potential is reached and the water produced by the reaction begins to crystallize in the cathode catalyst layer. This phenomenon is called the Frost Stage. The latter can be observed in a first stage through a dispersion of the cell voltages, and then through a collapse of the most affected cells. The impedance spectra can also be considered: the beginning of the frost stage can be detected through the translation to the right of the high frequency intersection point of the Nyquist plot with the real axis, first slowly and then quickly. The phenomenon can also be observed in Fig. 4 a1/b1/c1/ on the plots of the $R 1, R 2, R 3$ resistances versus the water produced. The electronic 
resistance decreases to a minimum value, then stabilises and finally increases exponentially. This behaviour is quite the same whatever the cold start temperature in the studied range. On the other hand, the temperature seems to have an influence on the behaviour of the low frequency resistance during the isothermal cold start. At $-5^{\circ} \mathrm{C}, R 3$ remains relatively stable during the hydration stage and the beginning of the frost stage while it increases quickly at $-10^{\circ} \mathrm{C}$ and immediately from the start at $-18^{\circ} \mathrm{C}$. After this last observation, it can be suggested that frost phenomena are already present in the catalyst layers even after purging. They are also more important at lower cold start temperatures because a larger amount of the liquid phase of water desorbs from the membranes during the cooling down. Note that the R3 value related with Point Nr. 11 in Fig. $4 \mathrm{c} 1$ can be considered as an outlier (it can be attributed to transient variations of operating conditions and to the difficult estimation of R3 because of the specific shape of Spectrum Nr. 11 at low frequencies).

A consequence of the frost stage can also be observed through the progressive growth of the capacitive arc in the impedance spectra displayed in Fig. 4. It can be deduced from this capacitive increase effect that the diffusion phenomena (mass-transfer) are hindered. The ice gradually invades the catalyst and gas diffusion layers, and finally induces oxygen starvation.

To conclude on these experimental results based on EIS performed during cold starts at $-5^{\circ} \mathrm{C},-10^{\circ} \mathrm{C}$, and $-18^{\circ} \mathrm{C}$, and with the assumption made before, some statements can be made:

- The cooling down of the previously dried membranes shows an increase of the electronic resistance which is still larger at lower temperatures. This phenomenon is a 
consequence of the decrease of the liquid phase of water inside the membranes due to desorption process.

- During the cold starts done at low current density, the electronic resistance begins to decrease in the hydration stage because the amount of water increases inside the membranes due to sorption process. Then, resistance finally increases sharply in the frost stage.

- The low frequency resistance behaviour depends on the cold start temperature and it is higher at lower temperatures. This phenomenon is probably linked to the presence of desorbed water which turns into crystallised water in active area during the cooling down. During the frost stage, the diffusion phenomena are gradually disrupted, which leads finally to oxygen starvation.

\subsection{Cyclic voltammetry and linear voltammetry results}

The CV diagrams allow identifying the electrochemical active area (ECA) of the considered electrode whereas the LSV graphs allow the detection of hydrogen crossover and internal shorting between anode and cathode. The aim is here to study the behaviour of the cathode ECA and the membrane tightness during both the conditioning process and the cold start experiment. These types of electrochemical characterisation techniques are usually used on single cells only. In our study, the experimental methods will be extended to the whole stack. A series of experiments has been done during a cold start at $-10^{\circ} \mathrm{C}$. For these experiments, as for the previous EIS tests, the Conditioning Process (CP) and the Cold Start Procedure (CSP) are respected. The results are given in Fig. 5 for the CV and in Fig. 6 for the LSV. Five CV and LSV characterisations are carried out. The first CV and LSV are realised at $20^{\circ} \mathrm{C}$ during the $\mathrm{CP}$ and just before the drying purge; they are considered as references. The four other 
tests are respectively performed: after the drying purge, after the cool down to $-10^{\circ} \mathrm{C}$, during the hydration stage and finally during the frost stage. During each characterisation sequence, the LSV measurement is first carried out, and then the CV is recorded. It can be observed in Fig. 5 that the ECA decreases by about $15 \%$ after the drying purge at $20^{\circ} \mathrm{C}$. As it is explained in $[21,22,23]$, the hygrometry rate at cathode has a large impact on the active surface area. A dry active area causes poor catalyst utilisation due to the proton immovability at low humidity. At the same time in Fig. 6, a reduction of the current crossover (Icross) can be noticed. It is reported in [24] that hydrogen current crossover decreases when the humidity of the membrane is reduced. According to the authors, this phenomenon would not be linked to the amount of the liquid phase of water inside the Nafion ${ }^{\circledR}$ membrane but to a decrease in the flexibility of the hydrophobic interfacial region of the membrane which would finally conduct to a decrease in gas permeability. The same tendency is noticed for the following CV and LSV diagrams recorded just after the cooling down to $-10^{\circ} \mathrm{C}$. The effect of the temperature drop is similar to the impact of the drying process. According to [24], the membrane flexibility is also affected by lower temperatures and again, the consequence is a lower gas permeability of the electrolyte polymer. It should be noted that [24] does not present results for temperature levels below $0^{\circ} \mathrm{C}$. 

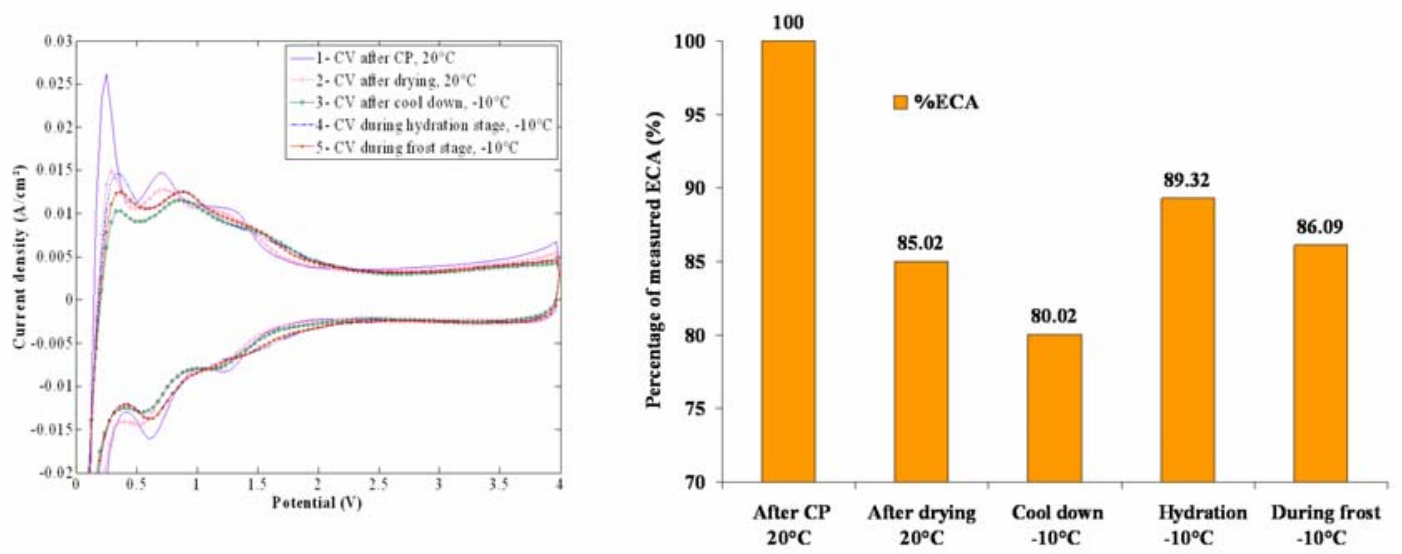

Fig. 5. CV results and evolution of ECA before and during a cold start at $-10^{\circ} \mathrm{C}$
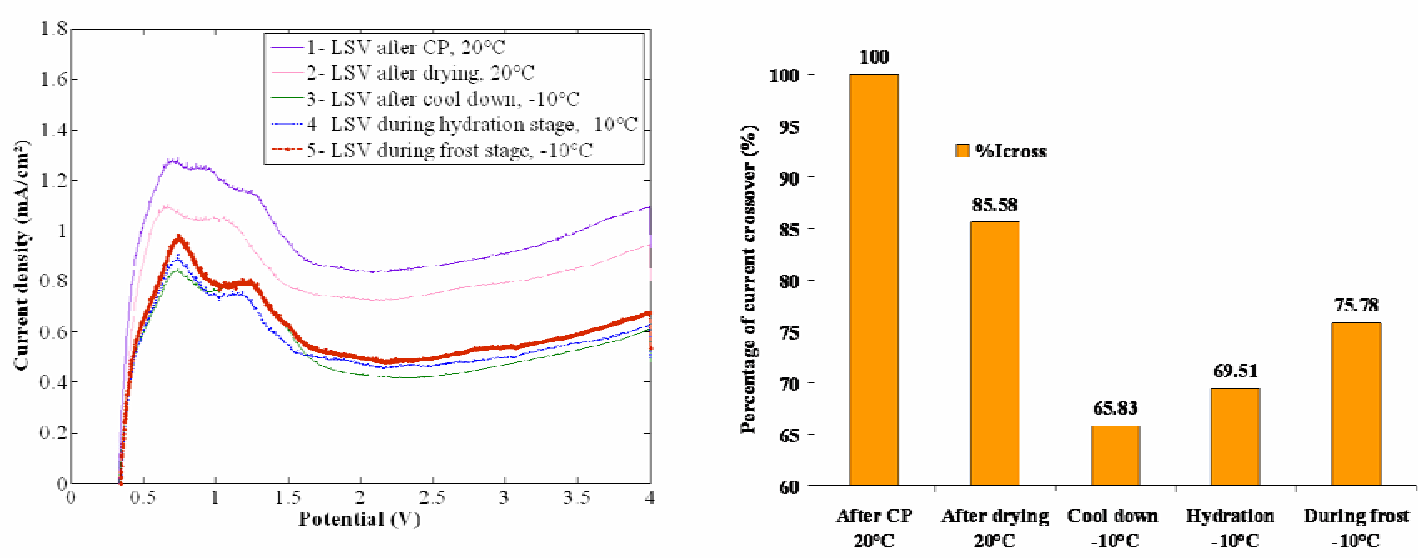

Fig. 6. LSV results and evolution of Icross before and during a cold start at $-10^{\circ} \mathrm{C}$

Concerning the ECA, the experiments conducted by Ge et al. in [14] in similar conditions do not show a loss of ECA. Their works show that the ECA remains almost the same at a $25^{\circ} \mathrm{C}$ ambient temperature and after cooling down to $-10^{\circ} \mathrm{C}$, and even after cooling down to $-20^{\circ} \mathrm{C}$ and $-30^{\circ} \mathrm{C}$. The explanation may be found by considering the amount of water in liquid phase inside the membrane after the gas purge. In our study, the purge of the stack is quite limited and its effect on the membrane conductivity is 
quite restricted $\left(R 1=5 \times R 1_{\text {nom }}\right)$. It is assumed with reference to [3] that some water desorbs out of the membrane during cooling down, crystallises inside the Cathode Catalyst Layer (CCL) and finally leads to the reduction of the Pt active area. The CSP is then performed until the amount of water produced by one cell reaches $0.45 \mathrm{mg} \cdot \mathrm{cm}^{-2}$. This value corresponds at $-10^{\circ} \mathrm{C}$ to the minimum value of the electronic resistance $R 1$ and to a fully hydrated state of the membranes as can be seen in Fig. 4 b1). Afterwards, the CSP is stopped; LSV and CV measurements are carried out. The results displayed in Fig. 5 and 6 show an increase in both the ECA and the current crossover value. One can assume here that the membranes have absorbed the major part of the water produced and even part of the crystallised water previously formed in the CCL. In the work of Li et al. [8], it is concluded that at the beginning of the cold start at $-25^{\circ} \mathrm{C}$, some higher temperatures generated locally by the chemical reaction and an ohmic heating could allow the ice to melt and move within the catalyst layer and finally be taken up by the membranes. The increase of the amount of the liquid phase of water inside the membranes causes more flexibility in the polymer and can account for the increase of the current crossover. Besides, the crystallised water absorbed in the CCL releases the action of Pt particles and the consequence is an increase of ECA. The CSP is then performed again and the FC operates in the frost stage. The process is stopped when the amount of water produced by one cell reaches $0.61 \mathrm{mg} \cdot \mathrm{cm}^{-2}$. At this value, the frost stage is just initiated but unfortunately the CSP has to be stopped sooner than expected due to a rise of pressure in the cathode compartment. The pressure drop is probably due to the water produced by the FC, obstructing the small exhausts located at the outlets of the air flow channel plates. Nevertheless, at this point, some new CV and LSV are performed. To reach this aim and in order to maintain constant the differential pressure 
in the FC, a back pressure is applied on the anode compartment. The pressure is then stabilised (iso-pressure operation) during these last electrochemical experiments so the value of pressure is higher than for the former ones. The CV and LSV results given in Fig. 5 and 6 show a decrease of the corresponding ECA and an increase in the current crossover value. The water produced crystallises inside the CCL and insulates Pt particles, which induces the loss of active area in the electrode. The current crossover level is here higher than in the former experiment but this phenomenon is probably linked to the higher pressure operation. Indeed, as it is reported in [24], fuel crossover current dependence versus gas pressure is clearly established.

To conclude on these experimental results based on the LSV and CV characterisations performed during the conditioning process before the cold start and during the cold start at $-10^{\circ} \mathrm{C}$, the following assessments can be made:

- A consequence of the drying process applied before a cold start is a loss of active area at cathode because of the poor catalyst utilisation due to the proton immovability at low humidity and a decrease of the hydrogen current crossover due to a decrease in the flexibility of the hydrophobic interfacial region of the membranes.

- The cooling down phase induces a loss of the active area at cathode related to the crystallization of desorbed water from the membranes and a decrease of the hydrogen current crossover attributed to an increase in stiffness of the membranes.

- During the cold start, the hydration stage of the membranes allows an increase in the ECA at cathode because a part of the crystallised water in the CCL is absorbed by membranes and releases the action of $\mathrm{Pt}$ particles. The amplitude of the current crossover is then higher due to an increase in flexibility of the membranes after sorption. 
- The effect of the frost stage during the cold start is a decrease of ECA at cathode related to the insulation of Pt particles by the crystallisation of water produced.

\subsection{Degradation effects}

In order to determine the consequences of the degradation linked to the different cold start experiments, some EIS measurements are done in nominal operating conditions, after each experiment. The main results are given in Fig. 7. Before the first cold start, the stack is operated three times in nominal conditions (i.e. using the CP without the purge stage nor the cooling down to temperature below $0^{\circ} \mathrm{C}$ ) in order to run-in it. The initial spectrum shown in Fig. 7 is the first one of this series. The second one is the Nyquist plot recorded after the first cold start at $-10^{\circ} \mathrm{C}$. This experiment is conducted after a suite of four cold starts at $-5^{\circ} \mathrm{C}$ for which ones there are only some slight evolutions of the resistances $R 2$ and $R 3$. The experiment at $-10^{\circ} \mathrm{C}$ marks a turning point in the behaviour of these resistances. After this test, in the experiments at $-15^{\circ} \mathrm{C}$ and $18^{\circ} \mathrm{C}, R 2$ and $R 3$ increase sharply and the size of the arcs on the spectra raises. The diffusion of the reactants and the transfer of charges are affected. Moreover, the electronic resistance $R 1$ follows a gradual increase since the first cold start.
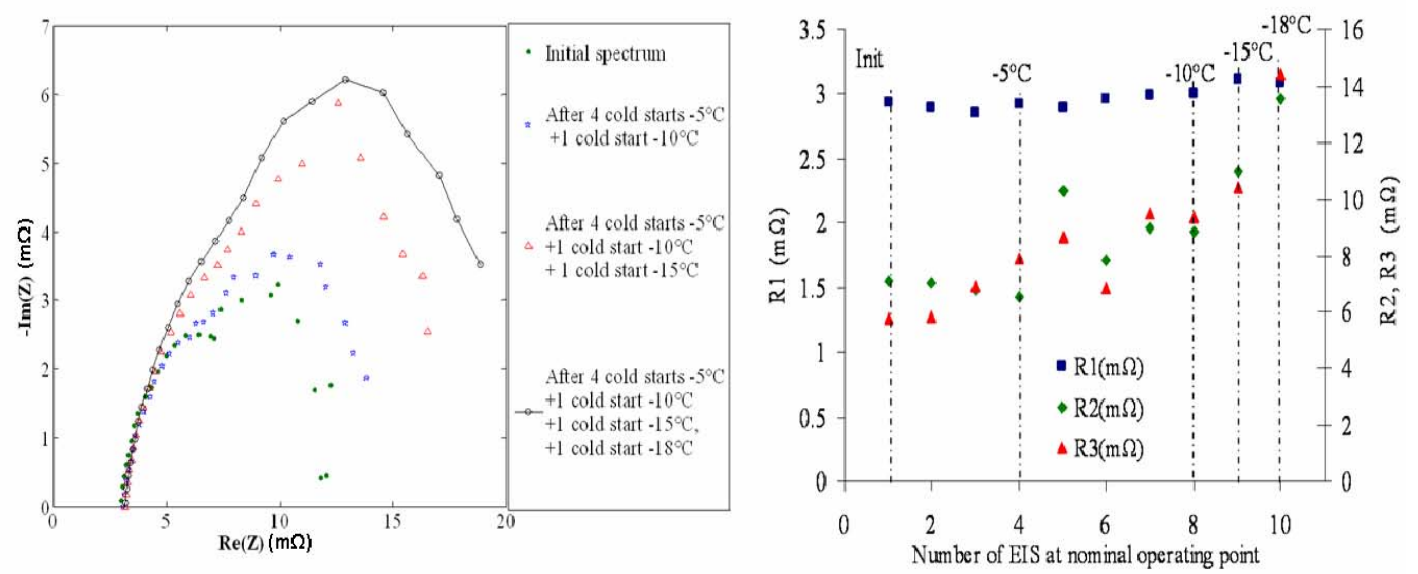

Fig. 7. EIS results at nominal operating point before and after cold starts 
An interesting point is the results of the EIS experiments performed in the same operating conditions on the best (Cellmax) and worst (Cellmin) cells in terms of electrical behaviour. The Nyquist plots are given in Fig. 8 and they show the gap of performances between the two cells. The measurements concern the tests carried out after the cold starts at $-10^{\circ} \mathrm{C},-15^{\circ} \mathrm{C}$ and $-18^{\circ} \mathrm{C}$. It is noticeable that one of the cells is mainly affected by the cold start experiments and concentrates most of the degradation in the complete FC assembly.

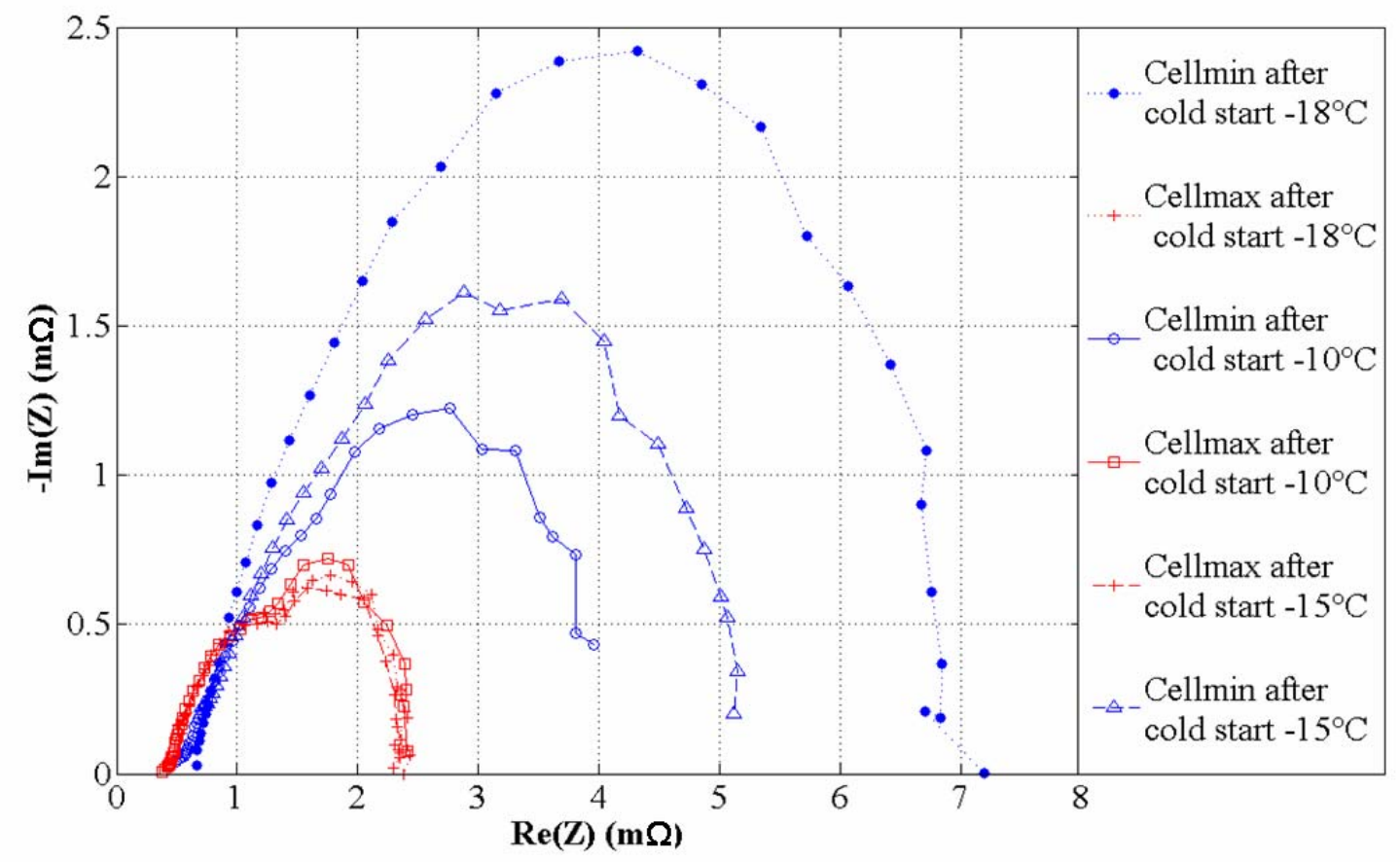

Fig. 8. EIS results at nominal operating point for worst (cellmin) and best (cellmax) cells in the stack after cold starts at $-10^{\circ} \mathrm{C},-15^{\circ} \mathrm{C}$ and $-18^{\circ} \mathrm{C}$

The measurements linked to the evolution of the individual cells show that a gradual degradation of the performances occurs, mainly in cells at one extremity of the stack. By considering the internal design of the investigated FC assembly (i.e. the position of 
the gas inlets and outlets located on the same side of the stack, the respective directions of the gas flow inside the assembly related to the geometry of the channel distributions in the bipolar plates), it can be stated that these cells are fed in last position by the reactants.

\section{Conclusion}

This article presents some test data and descriptions related to the behaviour of a short PEMFC stack operated in cold start. In the work proposed, the purpose is not to reach successful FC start-up, rather to investigate the evolution of the stack behaviour before, during and after cold starts. Some EIS experiments performed in cold temperature conditions highlight the evolutions of the electronic, charge-transfer and low frequency resistances. By this means, two distinct operating stages can be clearly distinguished during the cold start: the hydration stage and the frost stage. In nominal operating conditions, the EIS measurements allow to assess the degradation of the FC performances and show that the diffusion process is hindered, mainly after cold starts performed at temperatures below $-5^{\circ} \mathrm{C}$. Besides, it is found that the degradation process concerns principally only one individual cell in the FC stack. Some CV and LSV experiments allow the evaluation of the behaviour of cathode ECA and current crossover during both the conditioning of the FC (including purging and cooling down phases) and cold start at $-10^{\circ} \mathrm{C}$. It is observed that the variations of the cathode ECA show a high dependence on the different stages of the experiment. Electrochemical characterisations during cold start demonstrate the ability of this type of methods to be applied on small stacks as well as single cells. Finally, they lead to a number of assumptions on how the frost occurs during cold start and on the consequences on the 
FC degradation. Taking into account the results of this experimental study and with the additional help of computational modelling dealing with frost processes and controls $[25,26]$, it is now possible to imagine some technical solutions and strategies to reach successful FC cold starts without need of external energy.

\section{Acknowledgments}

This work was sponsored by the French Agence Nationale de la Recherche (ANR), PAN H MEPHISTO program. It was realised within the FC LAB institute.

\section{References}

[1] R. K. Ahluwalia, X. Wang, Rapid self-start of polymer electrolyte fuel cell stacks from subfreezing temperatures, J. of Power Sources 162 (2006) 502-512.

[2] A. A. Pesaran, G. H. Kim, J. D. Gonder, Milestone Report NREL/MP-540-38760 PEM Fuel Cell Freeze and Rapid Startup Investigation, (2005).

[3] M. Pineri, G. Gebel, R. J. Davies, O. Diat, Water sorption-desorption in Nafion ${ }^{\circledR}$ membranes at low temperature, probed by micro X-ray diffraction, J. of Power Sources $172(2007)$ 587-596.

[4] E. Pinton, Y. Fourneron, S. Rosini, L. Antoni, Experimental and theoretical investigations on a proton exchange membrane fuel cell starting up at subzero temperatures, J. of Power Sources 186 (2009) 80-88.

[5] C. Chacko, R. Ramasamy, S. Kim, M. Khandelwal, M. Mench, Characteristic Behavior of polymer Electrolyte Fuel Cell Resistance during Cold start, $J$. Electrochem. Soc. 155 (2008) 1145-1154. 
[6] K. Tajiri, Y. Tabuchi, F. Kagami, S. Takahashi, K. Yoshizawa, W. Chao-Yang, Effects of operating and design parameters on PEFC cold start, J. of Power Sources 165 (2007) 279-286.

[7] K. Tajiri, T. Tabuchi, C-Y. Wang, Isothermal cold start of polymer electrolyte fuel cell, J. Electrochem. Soc. 154 (2007) 147-152.

[8] J. Li, S. Lee, J. Roberts, Ice formation and distribution in the catalyst layer during freeze-start process - CRYO-SEM investigation, Electrochimica Acta 53 (2008) $5391-5396$

[9] J. Hou, B. Yi, H. Yu, L. Hao, W. Song, Y. Fu, Z. Shao, Investigation of resided water effects on PEM fuel cell after cold start, Int. J. Hydrogen Energy 32 (2007) 4503-4509.

[10] J. Hou, H. Yu, S. Zhang, S. Sun, H. Wang, B. Yi, P. Ming, Analysis of PEMFC freeze degradation at $-20^{\circ} \mathrm{C}$ after gas purging, J. of Power Sources 162 (2006) 513-520.

[11] E. A. Cho, J. J. Ko, H. Y. Ha, S. A. Hong, K. Y. Lee, T. W. Lim, I. H. Oh, Characteristics of the PEMFC Repetitively Brought to Temperatures below $0^{\circ} \mathrm{C}$, J. Electrochem. Soc. 150 (2003) 1667-1670.

[12] M. Oszcipok, D. Riemann, U. Kronenwett, M. Kreideweis, M. Zedda, Statistic analysis of operational influences on the cold start behaviour of PEM fuel cells, $J$. of Power Sources 145 (2005) 407-415.

[13] H. Wang, J. Hou, H. Yu, S. Sun, Effects of reverse voltage and subzero startup on the membrane electrode assembly of a PEMFC, J. of Power Sources 165 (2007) 287-292. 
[14] S. Ge, C. Y. Wang, Cyclic voltammetry study of ice formation in the PEFC catalyst layer during cold start, J. Electrochem. Soc. 154 (2007) 1399-1406.

[15] S. Bégot, F. Harel, J. M. Kauffmann, Experimental Studies on the Influence of Operational Parameters on the Cold Start of a 2kW Fuel Cell, Fuel Cells From Fundamentals to Systems 2 (2008) 138-150.

[16] E. Schießwohl, T. von Unwerth, F. Seyfried, D. Brüggemann, Experimental investigation of parameters influencing the freeze start ability of a fuel cell system, J. of Power Sources 193 (2009) 107-115.

[17] M. Oszcipok, M. Zedda, D. Riemann, D. Geckeler, Low temperature operation and influence parameters on the cold stat ability of portable PEMFCs, J. of Power Sources 154 (2006) 404-411.

[18] D. Hissel, M. C. Péra, D. Candusso, F. Harel, S. Bégot, Characterisation of polymer electrolyte fuel cells for embedded generators - Test bench design and methodology, in: X. W. Zhang (Ed.), Adv. in Fuel Cells, Research signpost, (2005) pp. 127-148.

[19] S. Bégot, F. Harel, J. M. Kauffmann, M. C. Péra, Freeze-thaw ageing effects on PEM fuel cells, FDFC Conference, Nancy, 10-12th December (2008).

[20] U. Retter, H. Lohse, Electrochemical impedance spectroscopie, in: F. Scholz (Ed.), Electroanalytical Methods - Guide to Experiments and Applications (2002) pp. 149-166.

[21] H-T. Kim, K-Y. Song, T.V. Reshetenko, S-I. Han, T-Y. Kim, S-Y. Cho, M-K. Min, G-S. Chai, S-C. Shin, Electrochemical analysis of polymer electrolyte membrane fuel cell operated with dry-air feed, J. of Power Sources 193 (2009) $515-522$. 
[22] R. Jiang, H. R. Kunz, J. M. Fenton, Investigation of membrane property and fuel cell behavior with sulfonated poly(ether ether ketone) electrolyte: Temperature and relative humidity effects, J. of Power Sources 150 (2005) 120-128.

[23] S. Wasterlain, D. Candusso, D. Hissel, F. Harel, P. Bergman, P. Menard, M. Anwar, Study of temperature, air dew point temperature and reactant flow effects on PEMFC performances using electrochemical spectroscopy and voltammetry techniques, J. of Power Sources 195 (2010) 984-993.

[24] M. Inaba, T. Kinumoto, M. Kiriake, R. Umebayashi, A. Tasaka, Z. Ogumi, Gas crossover and membrane degradation in polymer electrolyte fuel cells, Electrochimica Acta 51 (2006) 5746-5753.

[25] K. Jiao, X. Li, Three-dimensional multiphase modelling of cold start processes in polymer electrolyte membrane fuel cells, Electrochimica Acta 54 (2009) 68766891.

[26] F. Jiang, C-Y. Wang, K-S. Chen, Current Ramping: a strategy for rapid start-up of PEMFCs from subfreezing environment, J. Electrochem. Soc. 157 (2010) 342347. 